\title{
ULTRASOUND GUIDED CLOSED REDUCTION VERSUS OPEN REDUCTION OF ZYGOMATIC ARCH IN ZYGOMATICOMAXILLARY FRACTURES
}

\author{
Tasneem A. Amer ${ }^{*}$ M.Sc, Ahmed A. Sharara 2 PhD, Nevien S. Mohamed 2 PhD, Riham M. \\ Eldibany 2 PhD, Mohamed M. El-shafei $3 P h D$.
}

\begin{abstract} fractures needs accurate diagnosis, accessible exposure, and precise rigid fixation ten patients (control group) via coronal approach with open reduction of zygomatic arch. postoperative ocular complications. reflect satisfactory arch reduction among both groups. but with considerable disadvantages.

KEYWORDS: ZMC fractures, Ultrasound guided reduction, Coronal incisions. RUNNING TITLE: Ultrasound guided reduction of zygomatic arch fractures.
\end{abstract}

INTRODUCTION: trauma of the zygomaticomaxillary complex (ZMC) has functional and aesthetic consequences. Management of ZMC fractures is considered one of the most debatable issues regarding classification, diagnosis and surgical technique.Precise management of the ZMC

OBJECTIVES: To compare between ultrasound guided closed reduction and open reduction of zygomatic arch in cases of ZMC fracture.

MATERIALS AND METHODS: This study was conducted on a sample of twenty patients who had fracture repair of ZMC. Ten of them (study group) were treated via direct peri-orbital approach with the use of intra-operative ultrasound to guide zygomatic arch reduction. While the other

Postoperative patient evaluation was performed with specific attention paid towards zygomatic arch reduction, nerve function, wound healing, and

RESULTS: Radiographic follow up showed no statistical significant difference between normal side and reduced side of zygomatic arch which

CONCLUSION: Ultrasonography is an effective method for guiding zygomatic arch reduction with other minimal incisions in cases of ZMC fracture. On the other hand, coronal incisions have advantages of giving excellent access to ZMC fracture with direct reduction of zygomatic arch

1 BDS, 2009, M.Sc.2015, Faculty of Dentistry, Alexandria University, Egypt.

2 Professor of Oral and Maxillofacial Surgery, Department of Oral and Maxillofacial Surgery Faculty of Dentistry, Alexandria University, Egypt.

3 Assistant professor of Diagnostic and Interventional Radiology, Department of Diagnostic and Interventional Radiology Faculty of medicine, Alexandria University, Egypt.

*Corresponding author

E-mail: tasneem.amer87@gmail.com

\section{INTRODUCTION}

Zygomatic complex fractures form around $45 \%$ of midface fractures (1) and can result into significant cosmetic and functional complaints such as trismus due to pressure on coronoid process, enophthalmos and numbness in case of injury of infraorbital(IO) nerve (2,3). In addition, zygomatic bone forms portion of the orbit, so ZMC fractures may be accompanied with orbital trauma, which results in orbital blow-out fractures and ophthalmic injuries such as diplopia with orbital content entrapment and limited ocular movements as well as enophthalmos or exophthalmos $(4,5)$. Treatment of ZMC fractures involves just follow up without intervention, closed reduction or open reduction with internal fixation (ORIF) $(6,7)$. Recently concern toward less invasive procedures has been emphasized to limit incisions which lead to minimal scars (8-9). The coronal approach allows exposure of the zygomatic arch (ZA) and zygomaticofrontal (ZF)suture and the lateral aspect of orbital wall. It gives access to anatomical (ORIF) of ZA.

The major downside is long duration of exposure than the direct approach, excessive blood loss, scar alopecia, scarring at the temporal region, temporal hollowing due to temporal fat atrophy and facial nerve weekness $(10,11)$.

ZMC fracture could be accessed through different minimal approaches. The inferior orbital margin could be exposed through subtarsal, subciliary, or transconjunctival incision $(12,13)$. The ZF suture is exposed through a blepharoplasty, lateral eye brow incision or lateral canthotomy. Zygomaticomaxillary (ZM) buttress can be reached through an intraoral approach in the sulcus (14).

$\mathrm{ZMC}$ fracture treatment is challenging as it requires balance between proper bone fixation and the potential outcomes of different approaches (15). Thus ZMC fractures management 
should be considered as facial aesthetic procedure and concern should be given to skin incisions which are used (16).

Despite that the ZF suture and inferior orbital rim (IOR) could be accessed during surgery as fractured sites; they do not reflect the position of the zygomatic bone adequately, Fracture of the ZA is usually treated blindly using bone elevators through Gillies or keen approaches (17). Therefore, intraoperative assessment is essential to attain accurate ZA reduction with a less invasive technique.

The assessment of ZA reduction cannot be directly examined during operation (18), palpation and click of reduced bone or intraoperative radiographs are used clinically as a guide for reduction of the fractured fragments .However, surgeon cannot depend only on palpation due to presence of edema which masks the degree of reduction, and intraoperative radiographs usually are difficult in positioning of the patient and come with risks of harmful radiation exposure (19). On the other hand, ultrasonograph (US) is reliable and accessible without these harmful radiations. US provides a real time clinical image which is reproducible and reflects the position of the fractured bone surface (20-22).Coronal flap allows exposure and fixation of the ZA and ZF suture. In addition to fixation of inferior orbital rim and ZM suture which allows 4point fixation of ZMC.

The purpose of this study was to compare between US guided closed reduction and open reduction of zygomatic arch in cases of ZMC fracture regarding arch reduction, orbital movement, wound healing, and postoperative ocular complications in both groups.

\section{MATERIALS AND METHODS}

Study design: The study was a Prospective Clinical trial that is registered in clinicaltrials.gov (ClinicalTrials.gov Identifier: NCT04218058). Twenty patients underwent this study .The clinical part of the study was performed after gaining the ethical clearance from the Ethics Committee, Faculty of Dentistry, Alexandria University. All patients signed an Informed Consent Form before undergoing the operation. Participants were selected from the Teaching Hospital of Alexandria University and were operated upon in the Oral and Maxillofacial Surgery Department.

All patients aged between 20 to 50 years old presenting with ZMC fractures that require reduction and fixation were included in this study. Patients were excluded if there is any infection at the site of fracture lines and if they are suffering from chronic systemic diseases such as metabolic bone disease or immunocompromised status.

After sample selection according to the inclusion and exclusion criteria; the patients were randomly allocated into two groups: study group (10 patients) in which direct peri-orbital approach was used to gain access to the fracture with the use of intraoperative US to guide closed ZA reduction and control group (10 patients) in which coronal approach was used to gain access to the fracture with open reduction and fixation of ZA.

Preoperative phase:

Comprehensive history and clinical examination were performed for all the patients. Preoperative Computed tomography was taken for all the patients.

Surgical phase:

- All patients were treated under general anaesthesia. The surgical field was scrubbed with surgical scrub solution, followed by draping of the patient with sterile towels exposing only the area of surgery.

Study group:

- The fracture lines were exposed through direct peri-orbital approaches with (ORIF) using mini plates. Plates were placed along vertical and horizontal buttresses of facial skeleton. Up to three anatomical points of fixation were used for ZMC fractures: FZ suture, IOR and ZM buttress (Fig.1,Fig.2).

- Lateral eyebrow, lateral canthotomy or existing wound incisions were used for FZ suture fixation.

- Subciliary, subtarsal or transconjunctival incisions were used for IOR fixation.

- For ZM buttress fractures, intraoral upper buccal vestibular incision was used. After appropriate incision blunt dissection was done and periosteal flap raised in buttress region to expose the fracture site Open reduction was done for the fractured segments.

- ZA was reduced guided by intraoperative US.

- US scanning was performed with a $12-\mathrm{MHz}$ linear transducer (GE Voluson I portable ultrasound, Kpi Healthcare, USA) (Fig.2-A). The linear transducer was positioned tangential and over the surface of the ZA (Fig.2-B).

- US real-time images were obtained to confirm the position of fragments during surgery and to show ZA reduction (Fig.2-C,D). The reduction was done using bone elevators passed through a local incision in the gingival sulcus.

- 3-0 vicryl was used for deep layers and 5-0 prolene for skin layer(Fig.3-A),intraoral incisions were sutured by 3-0 vicryl.

After reduction, protection of the reduced ZA was done by oropharyngeal airway to avoid displacement of the arch (Fig3-B). Oropharyngeal airway was fixed using adhesive tape and was kept in place for one day until the patient is totally aware and able to avoid pressure on the operated side. Then patients were advised to use it during sleeping only (The main idea was to protect the arch during recovery from anesthesia).

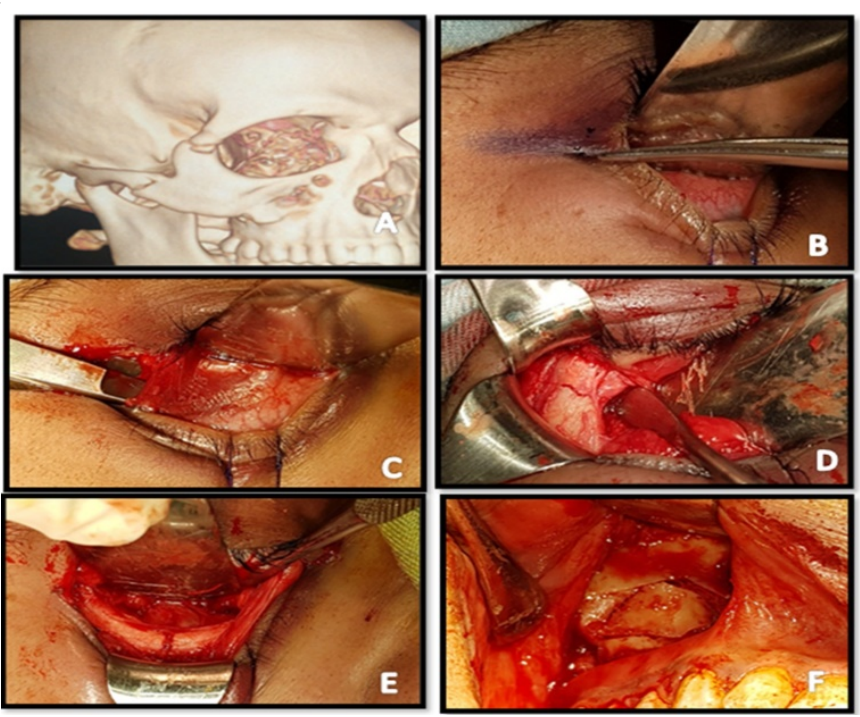

Figure (1):

A) preoperative 3DCT showing ZMC fracture.

B) lateral canthotomy. 
C)inferior cantholysis.

$\mathrm{D}, \mathrm{E})$ reduction of $\mathrm{FZ}$, infraorbital fracture lines.

F) intraoral incision showing reduction ZM fractuer.
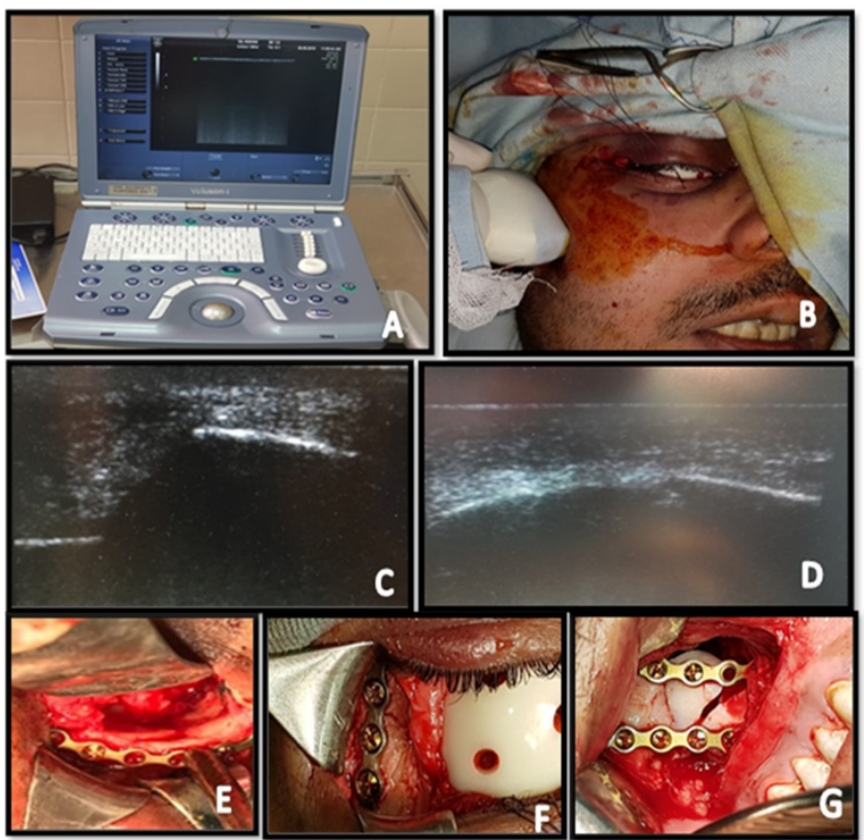

Figure (2):

A) A photograph showing GE Voluson 1 portable ultrasound.

B) A photograph showing linear transducer positioned over and tangential to the surface of the zygomatic arch.

C) Ultrasound image of displaced zygomatic arch.

D) zygomatic arch after reduction guided by ultrasound.

E,F,G) fixation of IOR,ZF,ZM fracture lines.
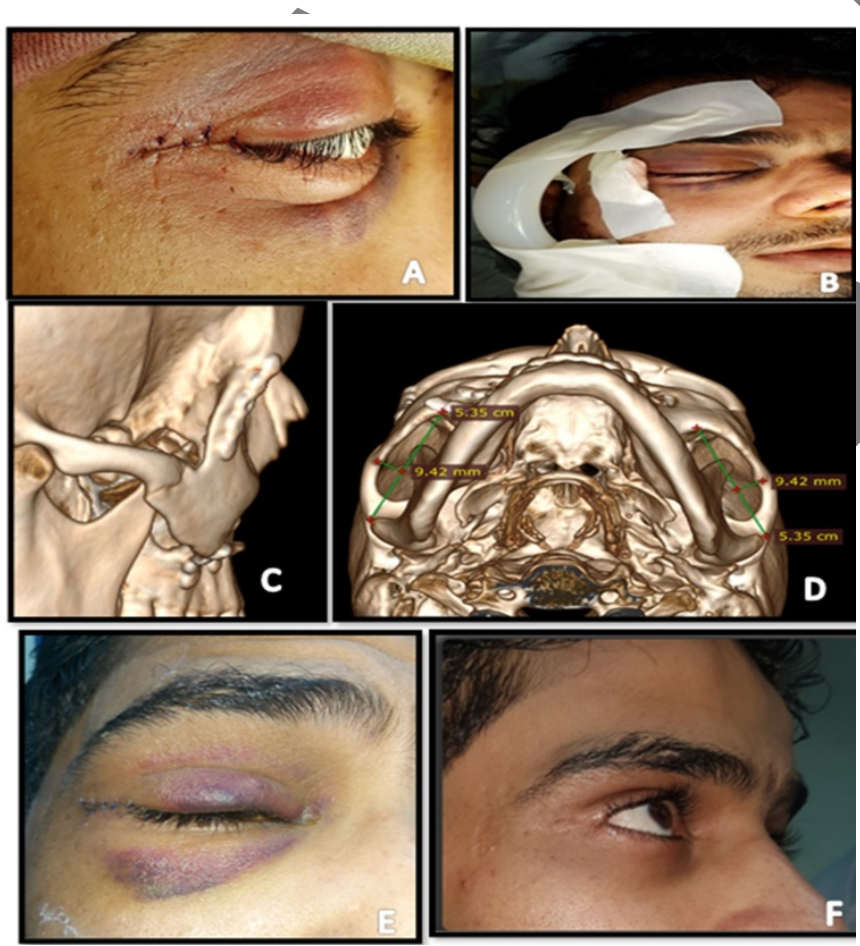

Figure (3):

A) Lateral canthotomy suturing using 5-0 prolene.

B) Protection of zygomatic arch by oropharyngeal airway.

C) Postoperative 3DCT showing zygomatic arch reduction.

D) 3DCT showing calculation of (HOA) in normal side and reduced side.

E) Postoperative clinical photographs showing circumorbital ecchymosis.

F) Clinical photographs showing healing of lateral canthotomy with minimal scar showing.

\section{Control group:}

- The fracture lines were exposed through coronal incision with preauricular extension for (ORIF) of the $\mathrm{ZA}$ and the FZ region (Fig.4).

- Fixation was performed using titanium miniplates and screws.

- ZM buttress fracture was managed intraorally.

- Wound debridement was done using saline irrigation. Patients treated using coronal flap approach needed low-pressure vacuum drain (redivac drain) to prevent hematoma formation under the flap.

- 3-0 vicryl was used for deep layers and 5-0 prolene for skin layer, intraoral incisions were sutured by 3-0 vicryl(Fig.5A,D).

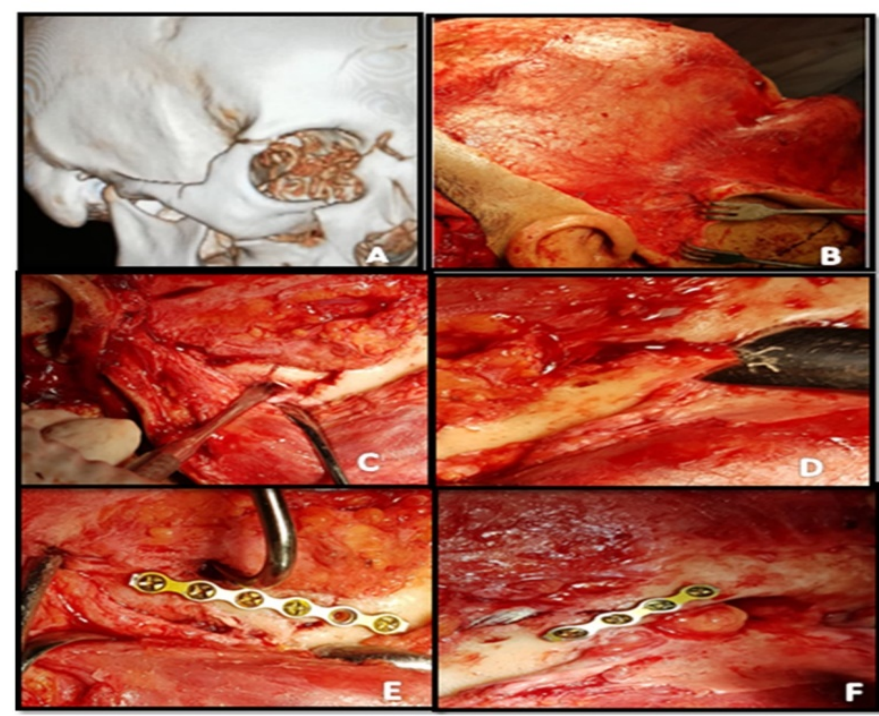

Figure (4):

A) 3DCT showing ZMC fracture

B) Reflection of coronal flap.

C) Photograph showing fractured zygomatic arch.

D) zygomaticofrontal fracture line.

E) Open reduction and fixation of zygomatic arch using mini-plate.

F) fixation of zygomaticofrontal fracture line.

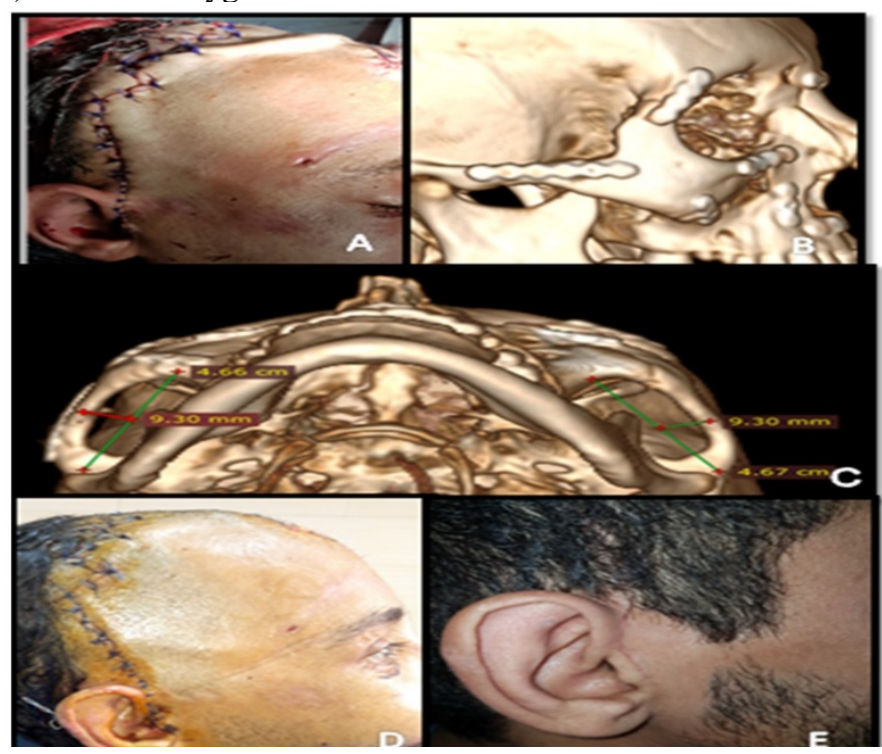


Figure (5):

A) photograph showing suturing of coronal flap.

B) postoperative 3DCT showing zygomatic arch reduction.

C) calculation of (HOA) in normal side and reduced side.

$\mathrm{D}$, E) clinical photographs showing coronal flap 1 week

,3months postoperatively.

\section{Post-operative phase:}

- Patients were instructed to use cold pack extra-orally starting immediately postoperatively.

- Postoperative medication included Amoxicillin + clavulanate 1 gm every 12 hours for the next 7 days (Augmentin, GlaxoSmithKline, UK), Metronidazole 500mg (Flagyl, GlaxoSmithKline, UK.) every eight hours for 7 days. $\alpha$-chemo-trypsin $5 \mathrm{mg}$ ( $\alpha$-chemotrypsin, Leurquin, France, packed by Amoun pharmaceutical company, Egypt) ampoules as antioedematous once daily for7 days. Diclofenac potassium 50mg (Cataflam, Novartis, Switzerland) every eight hours for 7 days. All patients were instructed to rinse their mouth using Chlorhexidine (Hexitol, ADCO, Egypt) antiseptic mouth. Instructions of soft, fully liquid, high protein, high calorie diet were given for all patients for 4 weeks postoperatively. Patients were instructed to maintain a good oral hygiene.

\section{Follow up phase}

For the evaluation of the clinical variables: pain, nerve function, wound healing and ocular complications. A systematic follow-up was implemented after 24 hours, 1week, 4 weeks and 3 months after surgery.

\section{Radiographic evaluation}

Radiographic examination was done through immediately postoperative computerized tomography (CT) to assess the adequacy of ZA reduction.

\section{Assessment of zygomatic arch reduction:}

The ZA arch is a curved bone structure, shaped like an arch bridge. Geometrically, A digitalized CT image was used to evaluate the degree of arch protruding. As in (Fig.5-C), a line extended from the anterior root to the posterior root of the ZA in the 3DCT represents the chord of the arch and the distance from most laterally protruding point to the chord is the height of the arch (HOA) (23).

The HOA was measured and compared postoperatively between affected side and normal side in both groups to reflect the degree of zygomatic arch reduction.

\section{Data analysis:}

All the obtained data was statistically analysed and presented in tables, graphs and charts using the (SPSS) version 20 (24). Number and percent were used to describe qualitative data. Range, mean, median and standard deviation were used to describe the quantitative data. The level of significance was at $5 \%$. ANOVA with repeated measures and T-test were used for the normally distributed quantitative data.

\section{RESULTS}

20 patients were registered in this study, ten of which were assigned for the study group and ten for the control group. The sample included 16 males and 4 females with male to female ratio 4:1 with age ranging from 20 to 50 years old with a mean of $27.5 \pm 6.25 y$ years in the study group and 31.1 \pm 5.85 years in control group.
$55 \%$ of cases (11cases) were due to road traffic accidents, while $30 \%$ of cases were caused by physical violence followed by falling from height representing $15 \%$ of cases.

\section{Clinical evaluation}

\section{Pain}

Pain was evaluated 24 hours after surgery, 1 week ,4 weeks and 3months to detect any pain according to a visual analogue scale (VAS) (25).

Pain intensity significantly decreased among all cases through-out the follow up periods ( $p$ value $<0.05$ ). There was significant difference in pain scores between the study and the control groups and the pain was completely relieved by the end of 4 weeks in both groups.

2. Ocular complications, wound healing, sensory nerve function

Wound dehiscence and infection did not occur in any of the cases. Also, no diplopia or ocular complications were observed. Postoperative circumorbital ecchymosis was transient and subsided subsequently.

Study group: $80 \%$ of the patients (8 cases) complained of numbness (paresthesia) of the lower eyelid, upper lip and lateral part of nose and skin of premaxillary region which is the IO nerve terminal branches. Six of these patients regained their normal sensation in the $4^{\text {th }}$ week of follow up and normal sensation has been regained at the $3^{\text {rd }}$ month in all cases.

Control group: $70 \%$ (7 cases) had immediate postoperative paraesthesia of the region of IO nerve terminal branches.

$40 \%$ (4 cases) were reported with defícit of temporal branch of facial nerve. (Temporal branch weakness: Assessed clinically by examination of frontal wrinkling, tight closure of the eyes) (Fig.6). Normal sensation was regained at the $4^{\text {th }}$ week of follow up in 6 patients, while one patient sustained minimal tingling sensation. Out of four patients suffered from deficit of temporal branch of facial nerve in the first week, three cases had regained their normal function. At the $3^{\text {rd }}$ month all the cases regained normal sensation. One case had persistent weakness of the temporal branch of facial nerve. Also,two cases (20\%) showed depression of the temporal fossa (temporal hollowing)

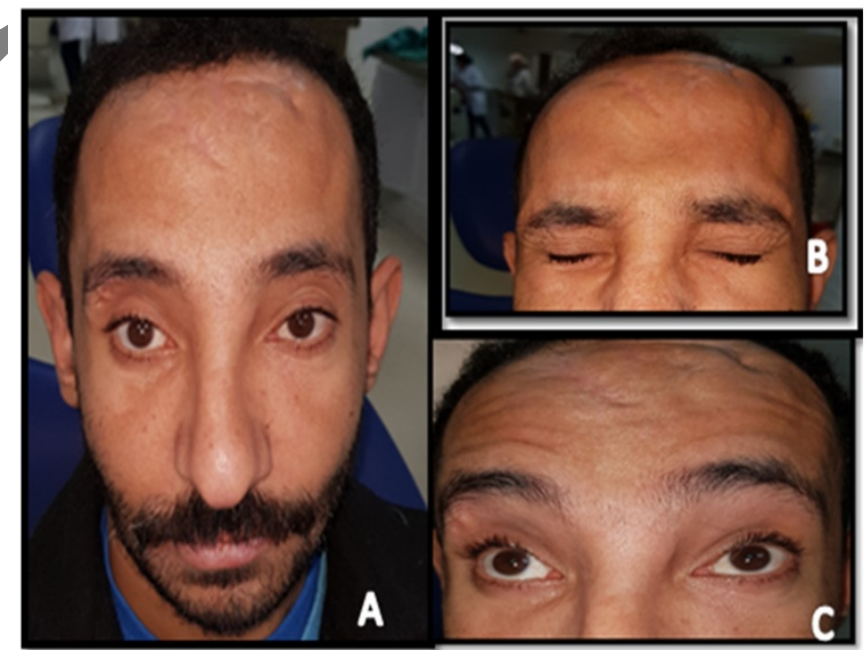

Figure (6):

A) postoperative clinical photograph showing coronal incision covered by normal hair.

B) $\mathrm{B}, \mathrm{C})$ clinical testing of temporal branch of facial nerve. 


\section{Radiographic evaluation}

All patients were examined postoperatively using computerized CT to evaluate the reduction of zygomatic arch. It was measured by comparing the HOA in the normal side and in the fractured side in both groups. There was no significant difference in both groups which reflects sufficient reduction of zygomatic arch (Table 1).

Table (1): Comparison between the (HOA) in the normal side and reduced side in both groups:

\begin{tabular}{|c|c|c|c|c|}
\hline & \multicolumn{2}{|c|}{ (HOA) in $\mathrm{mm}$} & \multirow[t]{2}{*}{ 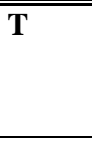 } & \multirow[t]{2}{*}{$\overline{\mathbf{P}}$} \\
\hline & Normal side & $\begin{array}{l}\text { Reduced } \\
\text { side }\end{array}$ & & \\
\hline $\begin{array}{l}\text { Study } \\
\text { group } \\
\text { Min. - } \\
\text { Max. } \\
\text { Mean } \pm \\
\text { SD. } \\
\text { Median }\end{array}$ & $\begin{array}{l}7.0-11.5 \\
8.91 \pm 1.3 \\
8.6\end{array}$ & $\begin{array}{l}7.2-11.3 \\
8.78 \pm 1.14 \\
8.5\end{array}$ & 0.225 & .412 \\
\hline $\begin{array}{l}\text { control } \\
\text { group } \\
\text { Min. - } \\
\text { Max. } \\
\text { Mean } \pm \\
\text { SD. } \\
\text { Median }\end{array}$ & $\begin{array}{l}7.8-11 \\
8.96 \pm 0.91 \\
8.75\end{array}$ & $\begin{array}{l}7.8-10 \\
8.89 \pm 0.66 \\
9\end{array}$ & & .427 \\
\hline
\end{tabular}

\section{t: Student t-test}

$\mathrm{p}$ : $\mathrm{p}$ value for comparing between the two groups

*: Statistically significant at $\mathrm{p} \leq 0.05$

\section{DISCUSSION}

This study was performed to evaluate the role of intraoperative ultrasound during ZA reduction in cases of ZMC fractures, and compare it with open reduction of the arch through coronal approach.

The descriptive analysis of the demographic data unveiled a mean age of $27.5 \pm 6.25$ years among the study group and a mean of $31.1 \pm 5.85$ years among the control group, ranging from 20 to 50 years and this is in agreement with other studies that the third and fourth decade groups of age in both sexes were significantly more likely to sustain facial fractures (26-28). Melek and Sharara (2016) (29) declared a mean age (25.56 \pm 14.04 years) and male to female ratio (4.5:1) this in agreement with this study as the male to female ratio was $4: 1$ with male prevalence at $80 \%$.

Road Traffic Accidents (RTA) were the most prevailing etiological factor with $55 \%(n=11)$, followed by falling from height $(30 \%, n=6)$ and interpersonal violence $(15 \%, n=3)$. There is an obvious agreement among authors that the most common cause of maxillofacial trauma all around the world is RTA (30).

Both study and control groups showed an uneventful follow up period as no infection, hematoma or globe complication was recorded. Regarding the postoperative sensory nerve function, the study group showed $80 \%$ (8 cases) of transient nerve affection presented as (paresthesia) of the upper lip, lower eyelid and lateral part of nose which is the area of IO nerve terminal branches. While, in the control group seven cases (70\%) showed the same nerve affection. This percentage is in agreement with the fact that the majority of patients have defect in the function of the IO nerve subsequent to ZMC fractures, because in $95 \%$ of ZMC fractures the fracture lines involve the IO foramen. The nerve can be damaged through ischaemia, traction, compression, oedema, or sharp margin of the fracture line (31).

The normal sensation was regained for 12 cases out of 15 cases in both groups by the end of the 4th week of follow up period. This may be justified as the state of the nerve compression and affection is a parameter that won't change by changing the approach utilized but rather by the accuracy of the reduction (31). All the patients regained their normal sensation at the end of this study. This result is in agreement with (Benoliel et al) who reported that most patients of IO nerve dysfunction following ZMC fractures will recover in case of open reduction, freeing the nerve from the compressing fractured segments and internal fixation (32). In this study $40 \%$ (4 cases) of control group were reported with deficit of temporal branch of facial nerve. Out of which three cases recovered within the 4th postoperative week, while in one case the temporal branch weakness persisted through the follow up period In the retrospective study by Zhang et al at 2006 (2) Six out of 69 cases had facial nerve weakness, and one case had a permanent deficit. Kumar et al (33) reported three out of ten patients with mild temporal nerve palsy out of which two cases recovered within the 2nd postoperative week while, in one case facial nerve palsy recovered by the end of 12th postoperative week. The finding of our study correlated with the above studies.

The ZA is considered the key in ZMC fracture repair as the correct alignment of the ZA guarantees sufficient projection of the lateral aspect of the face and avoids changing of the facial width (34).

In our study by comparing the height of the arch in the normal side and reduced side on post-operative 3DCT there was no significant difference which reflects sufficient reduction of ZA.

During the repositioning of fractured segments ZA assessment using US was satisfactory in all cases except one case. Imagining of the ZA during reduction showed correct alignment and confirmed the proper arch projection. Fracture repair under US control led to excellent results in 9 out of 10 patients. The final US images matched exactly the postoperative CT images. In the 10th patient, the assessment of the ZA contour was difficult; due to emphysema which confused the image interpretation. The ZA in this case was over reduced which was accepted as there was no interference with coronoid process.

The value of intraoperative US in repositioning of the ZA is evident and the technique is easily performed, the repositioning maneuver takes about $7 \mathrm{~min}$.

As (Gulicher et al) claimed that ultrasonography is considered a highly effective imaging technique for intraoperative guided reduction, enabling assessment of alignment of the $\mathrm{ZA}$ and the facial projection of the zygomatic body(17). 
In the study group $90 \%$ of patients the ZA fractures were clearly detected by ultrasound. The sensitivity and the value of fracture detection were both excellent. These results confirm this method to be a useful visualizing tool for fractures of the ZA as reported by McCann et al (35).

Also, the control group showed no significant statistical difference between normal and reduced site according to HOA which reveal comparatively satisfactory fragment reduction.

On one hand, coronal flaps propose advantages such as: wide exposure to ensure accessibility for anatomical reduction and to avoid nonunion or malunion in patients with ZMC fracture. On the other hand, this approach has drawbacks such as haemorrhage, noticeable scars, lengthy operation, paraesthesia in the operated region, temporal nerve deficit and temporal hollowing (36). Therefore, the indications for coronal incisions should be considered.

These conclusions indicate that reasonably satisfactory results can be obtained without direct reduction and fixation and through guided reduction of ZA in ZMC fractures (37).

\section{CONCLUSION}

ZMC fractures can be quite challenging to manage. Their complex 3D nature and location make them difficult to reduce and fixate. It is better to use the least number of incisions and fixation points as possible to achieve a stable reduction and fixation. Ultrasonography is a very rapid, economical, and free of radiation imaging technique for detection of zygomatic arch. Ultrasonography is also considered an effective method for intraoperative guided zygomatic arch reduction. Coronal incision has advantages of giving excellent access to the ZMC fracture but with considerable disadvantages.

\section{The authors declare that they have no conflicts of interest.}

\section{REFERENCES}

1. Kovacs A, Ghahremani M: Minimization of zygomatic complex fracture treatment. Int J Oral Maxillofac Surg. 2001; 30: 380.

2. Zhang Q, Dong Y, Zu-Bing L, Zhao J: Coronal incision for treating zygomatic complex fractures. J Cranio Maxillofac Surg. 2006; 34:182.

3. Chen C: Endoscopic zygomatic fracture repair. Plast Reconst Surg. 1998; 5: 282.

4. Nkenke E, Benz M, Maier T, Wiltfang J, Holbach L, Kramer M. Relative en- and exophthalmometry in zygomatic fractures comparing optical non-contact, nonionizing 3D imaging to the Hertel instrument and computed tomography. J Cranio Maxillofacial Surg. 2003; 31:362

5. Nkenke E, Benz M, Maier T, Wiltfang J, Holbach L, Kramer M, Gerd H, Neukam F: Hertel exophthalmometry versus computed tomography and optical 3D imaging for the determination of the globe position in zygomatic fractures. Int J Oral Maxillofac Surg. 2004; 33: 125.

6. El-Anwar MW, Elsheikh E, Sweed AH, Ezzeldin N. Electromyography assessment in zygomaticomaxillary complex fractures. Oral and Maxillofacial Surgery 2015;19(4):375-9
7. Meslemani D, Kellman RM. Zygomaticomaxillary complex fractures. Arch Facial Plast Surg 2012;14:62-6

8. Tarabichi M. Transsinus reduction and one-point fixation of malar fractures. Arch Otolaryngol Head Neck Surg 1994; 120: 620-5.

9. Soejima K, Sakurai H, Nozaki M, et al. Semi-closed reduction of tripod fractures of zygoma under intraoperative assessment using ultrasonography. J Plast Reconstr Aesthet Surg 2009; 62: 499-505.

10. Choi KY, Ryu DW, Yang JD, Chung HY. Feasibility of 4-point fixation using the preauricular approach in a zygomaticomaxillary complex fracture.J Craniofac Surg. 2013;24(2):557-62.

11. Ohjimi H, Taniguchi Y, Tanahashi S, Era K, Fukushima T. Accessing the Orbital Roof via an Eyelid Incision: The Transpalpebral Approach. Skull base surgery. 2000;10(4):211-216

12. El-Anwar M, Elsheikh E, Hussein A,Tantawy A, Abdelbaki Y. Transconjunctival versus subciliary approach to the infraorbital margin for open reduction of zygomaticomaxillary complex fractures: a randomized feasibility study. Oral Maxillofac Surg. 2017; 21:187-92.

13. Salgarelli AC, Bellini P, Landini B, Multinu A, Consolo U. A comparative study of different approaches in the treatment of orbital trauma: an experience based on 274 cases. Oral Maxillofac Surg. 2010; 14:23-7.

14. Carvalho A C, Pereira C C, Queiroz T P, Magro-Filho O. Intraoral approach to zygomatic fracture: modified technique for infraorbital rim fixation. J Craniofac Surg. 2012;23(2):537-538.

15. Manson P N, Clark N, Robertson B. Comprehensive management of pan-facial fractures. J Craniomaxillofac Trauma. 1995;1(1):43-56.

16. Raschke G F, Rieger U M, Bader R D. et al. The zygomaticomaxillary complex fracture - an anthropometric appraisal of surgical outcomes. J Craniomaxillofac Surg. 2013;41(4):331-337.

17. Gulicher D, Krimmel M, Reinert S: The role of intraoperative ultrasonography in zygomatic complex fracture repair. Int J Oral Maxillofac Surg. 2006; 35: 224.

18. Heiland M, Schmelzle R, Hebecker A, Schulze D: Intraoperative $3 \mathrm{D}$ imaging of the facial skeleton using the SIREMOBIL Iso-C3D. Dentomaxillofac Radiol. 2004; 33: 130.

19. Archer, W. H.: Fractures of the facial bones and their treatment. In: Archer, W. H. (ed.): Oral and maxillofacial surgery. Saunders, Philadelphia(1975) 1274.

20. Adeyemoa W, Akadirib O. A systematic review of the diagnostic role of ultrasonography in maxillofacial fractures.Int J Oral Maxillofac Surg.2011;40(7): 655-61.

21. Rama K, Koteswara N, Leela G, Santosh V, Ranganath N, Vijaya U. Role of Ultrasonography in Oral and Maxillofacial Surgery: A Review of Literature. J. Oral Maxillofac. Surg.2015;14(2):162-70.

22. Akizuki H, Yoshida H, Michi K.Ultrasonographic evaluation during reduction of zygomatic arch fractures.J Craniomaxillofac Surg. 1990;18(6):263-6.

23. Ma F, Tang S. Zygomatic arch reduction and malarplasty with multiple osteotomies: its geometric considerations. Aesthetic Plast Surg. 2014;38(6):1143-50. 
24. Kirkpatrick LA, Feeney BC. A simple guide to IBM SPSS: for version 20.0. 12th ed. USA. Wadsworth cengage learning; 2012.

25. Johnson C. Measuring Pain. Visual Analog Scale Versus Numeric Pain Scale: What is the Difference? J Chiropr Med. 2005;4(1):43-4.

26. van den Bergh B, Karagozoglu KH, Heymans MW, Forouzanfar T. Aetiology and incidence of maxillofacial trauma in Amsterdam: a retrospective analysis of 579 patients. J Craniomaxillofac Surg. 2012;40(6):e165-9.

27. Salentijn EG, van den Bergh B, Forouzanfar T. A ten-year analysis of midfacial fractures. J Craniomaxillofac Surg. 2013;41(7):630-6.

28. Sakr K, Farag IA, Zeitoun IM. Review of 509 mandibular fractures treated at the University Hospital, Alexandria, Egypt. Br J Oral Maxillofac Surg. 2006;44(2):107-11.

29. Melek LN, Sharara AA. Retrospective study of maxillofacial trauma in Alexandria University: Analysis of 177 cases. Tanta Dent J. 2016;13(1):28.

30. Boffano P, Kommers SC, Karagozoglu KH, Forouzanfar T. Aetiology of maxillofacial fractures: a review of published studies during the last 30 years. $\mathrm{Br} J$ Oral Maxillofac Surg. 2014;52(10):901-6.

31. Vriens JP, Moos KF. Morbidity of the infraorbital nerve following orbitozygomatic complex fractures. J Craniomaxillofac Surg. 1995;23(6):363-8.
32. Benoliel R, Birenboim R, Regev E, Eliav E. Neurosensory changes in the infraorbital nerve following zygomatic fractures. Oral Surg Oral Med Oral Pathol Oral Radiol Endod. 2005;99(6):657-65.

33. Kumar VS, Rao NK, Mohan KR, Krishna L, Prasad BS, Ranganadh N, et al. Minimizing complications associated with coronal approach by application of various modifications in surgical technique for treating facial trauma: A prospective study. Natl J Maxillofac Surg. 2016;7(1):21-8.

34. Lew DH, Park BY, Lee HB, Lew JD. Simple fixation method for unstable zygomatic arch fracture using double Kirschner's wires. Plast Reconstr Surg. 1998;101(5):1351-4.

35. McCann PJ, Brocklebank LM, Ayoub AF. Assessment of zygomatico-orbital complex fractures using ultrasonography. Br J Oral Maxillofac Surg. 2000;38(5):5259.

36. Kurita M, Okazaki M, Ozaki M, Tanaka Y, Tsuji N, Takushima A, et al. Patient satisfaction after open reduction and internal fixation of zygomatic bone fractures. J Craniofac Surg. 2010;21(1):45-9.

37. Cheon JS, Seo BN, Yang JY, Son KM. Clinical Followup on Sagittal Fracture at the Temporal Root of the Zygomatic Arch: Does It Need Open Reduction? Arch Plast Surg. 2013;40(5):546-52.

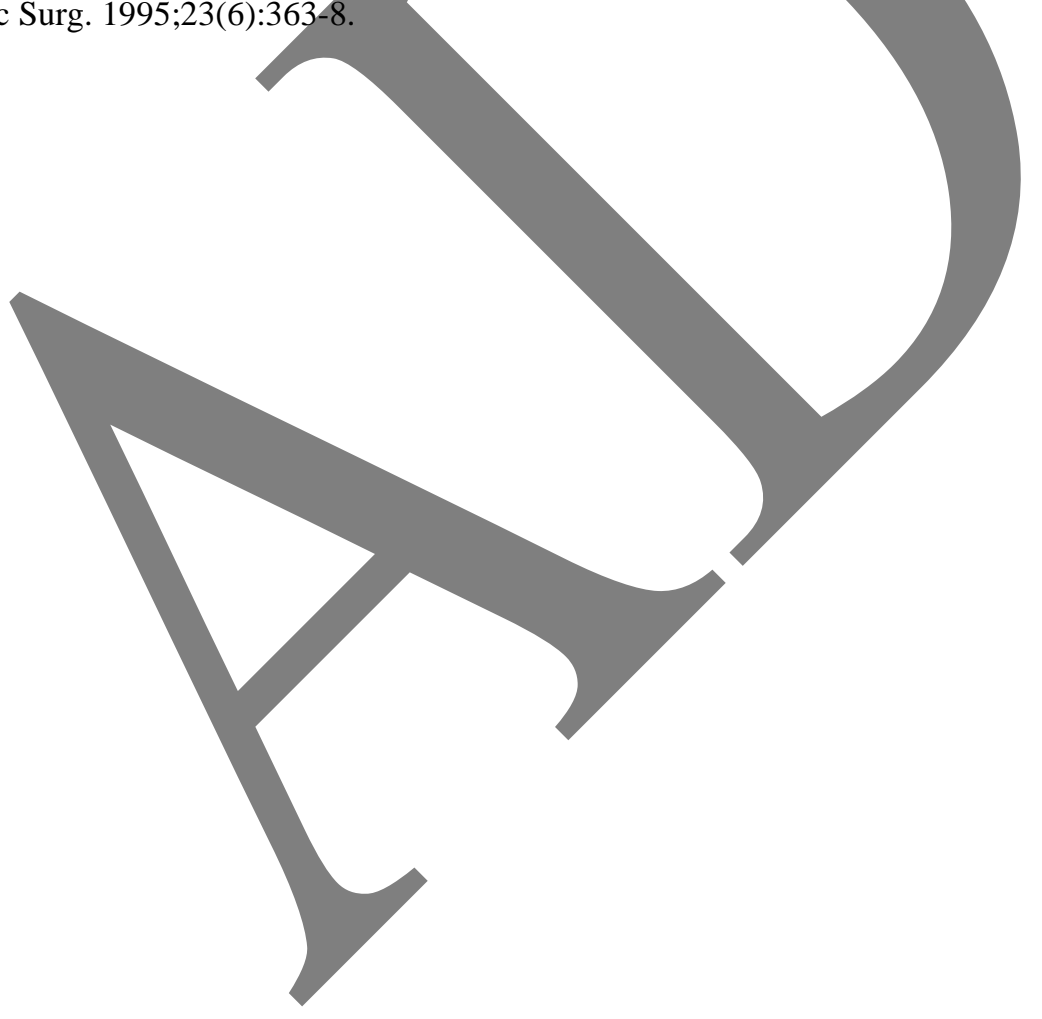

